\begin{tabular}{ll|l}
\cline { 2 - 3 } & \multicolumn{2}{l}{ Intervent Neurol 2016;5:111-117 } \\
\cline { 2 - 3 } & $\begin{array}{l}\text { DOI: 10.1159/000446795 2016 S. Karger AG, Basel } \\
\text { Published online: June 4, 2016 }\end{array}$ & $\begin{array}{l}\text { (C) } 2664-9737 / 16 / 0054-0111 \$ 39.50 / 0 \\
\text { www.karger.com/ine }\end{array}$ \\
\hline
\end{tabular}

\title{
Stent Retriever-Based Thrombectomy in Octogenarians
}

\author{
Jose E. Cohen ${ }^{\mathrm{b}}$ John M. Gomori ${ }^{\mathrm{a}}$ Ronen. R. Leker ${ }^{\mathrm{c}}$ \\ Departments of a Neurosurgery, ${ }^{b}$ Radiology and ${ }^{c}$ Neurology, Hadassah-Hebrew University \\ Medical Center, Jerusalem, Israel
}

\section{Key Words}

Endovascular · Octogenarians · Reperfusion · Stroke · Thrombectomy

\begin{abstract}
Background and Aims: Stent retriever-based thrombectomy (SRT) may be beneficial in patients with large hemispheric stroke. Previous studies concluded that favorable outcomes are far less frequent after endovascular therapy in older patients but have not explored outcomes in the era of newer-generation stent retrievers. Materials and Methods: Consecutive patients with large hemispheric stroke treated with SRT were included. We compared neurological and functional outcomes between patients younger and older than 80. Results: We included 16 patients older than 80 (22.5\%, mean age $84.1 \pm 4.4,56 \%$ females) and compared them to 55 patients that were younger than 80 (77.5\%, mean age $63.1 \pm 12.5,51 \%$ females). Risk factor profile, admission neurological severity, stroke etiology and procedure-related variables including excellent target vessel recanalization did not differ between the groups. Favorable outcome at 90 days (modified Rankin score $\leq 2$ ) was more common in younger patients (77 vs. $23 \% ; p=0.031$ ). In contrast, mortality rates were higher in octogenarians ( 40 vs. $7 \% ; p=$ 0.01). Logistic regression analysis adjusting for neurological severity and collateral state identified age over 80 (odds ratio, OR $0.15,95 \%$ CI $0.03-0.75 ; p=0.02$ ) and reperfusion state (OR 7.4, 95\% CI 1.1-49.9; $p=0.04$ ) as significant modifiers of favorable outcome. Similarly, age over 80 was identified as a positive predictor of mortality (OR 8.1, 95\% CI 1.8-36.7; $p=0.007$ ). Conclusions: Octogenarians have higher chances of mortality and lower probability of achieving functional independence even after SRT. Nevertheless, because some elderly patients do achieve favorable outcomes, the cost-effectiveness of SRT in this population needs to be further studied.




\section{Introduction}

Large hemispheric ischemic stroke secondary to internal carotid or proximal middle cerebral artery occlusions carries a mortality rate of close to $80 \%$ if left untreated $[1,2]$. Systemic thrombolysis is of limited benefit in these patients [3-6], but endovascular reperfusion therapy has recently proved effective in several prospective studies [7-12] that used rigorous selection criteria and mandated an independent premorbid state for inclusion. Most previous series evaluating this technique in large hemispheric strokes only included relatively younger patients with 80 being the usual upper age limit [13-16], and studies that did include older patients have shown that the rates of favorable outcome are considerably lower in patients older than 80, despite adequate vessel recanalization [17-19]. However, most of these studies used older techniques for reperfusion, while the advent of newer-generation stent retriever-based thrombectomy (SRT) allows for more rapid and complete target vessel recanalization and tissue reperfusion [20]. Furthermore, the life expectancy in most countries is constantly increasing and clinicians will likely be faced with many more patients presenting with large stroke who are older than 80 . Therefore, we aimed to evaluate whether octogenarian patients also benefit from SRT if it would become widely available.

\section{Patients and Methods}

We prospectively recruited consecutive patients presenting with large hemispheric stroke that underwent SRT over the span of 2 years from 2013 to 2015 into our stroke registry and the data was retrospectively analyzed. The institutional review board authorized anonymous inclusion of patients into the consecutive database without getting informed consent.

To be eligible for SRT, patients had to have an initial National Institutes of Health Stroke Scale (NIHSS) score $>10$ and to be previously independent [modified Rankin score (mRS) <2]. Furthermore, all included patients were treated within $8 \mathrm{~h}$ of stroke onset. The diagnosis of internal carotid or proximal middle cerebral artery occlusion was established according to clinical findings that included hemiparesis/hemiplegia, sensory symptoms and evidence for cortical involvement such as aphasia, neglect or hemianopsia in various combinations. The diagnosis of large vessel occlusion had to be proven on computed tomography (CT) angiography (CTA), magnetic resonance angiography or digital subtraction angiography in all patients. Exclusion criteria included evidence of large hemispheric infarction on the admission CT defined as hypodensity covering more than $1 / 3$ of the middle cerebral artery territory, international normalized ratio $>3$ and existing disease with limited life expectancy (e.g. terminal cancer). Patients with small vessel disease were excluded, as were those presenting in deep coma and those with primary intracerebral or subarachnoid hemorrhage.

In this study, we compared patients that were younger than 80 at the time of presentation to those older than 80. Clinical and demographic characteristics accrued included cerebrovascular risk profile, concomitant medications, time from symptom onset to initiation of endovascular procedure and time from onset to reperfusion. Infarct etiology was classified according to the Trial of ORG 10172 in Acute Stroke Treatment (TOAST) criteria as cardioembolic, large artery atherothrombotic, other classified (e.g. dissection) or unclassified [21].

All patients were admitted to the intensive care unit for at least $24 \mathrm{~h}$ post procedure. Neurological deficits were determined with the NIHSS [22], and functional deficits before admission and at 90 days post infarct were evaluated with the mRS [23]. Favorable outcome was defined as an mRS $\leq 2$.

Radiological parameters were evaluated on entry CT/magnetic resonance imaging and on the diagnostic and therapeutic angiography and follow-up CT/CTA. Flow was classified with the thrombolysis in cerebral infarction (TICI) scale and TICI $2 \mathrm{~b}-3$ was considered as favorable recanalization and reperfusion [24]. Collateral flow was classified with the ASITN/SIR Collateral Flow Grading System on pretreatment angiography [24]. The score was dichotomized into poor (grades $0-2 ; 0=$ no collaterals, $1=$ slow collaterals to the periphery of the ischemic area, 2 = rapid collaterals to the periphery of ischemic site with persistence of some of the defect and to only a portion of the ischemic territory), and favorable (grades 3-4; $3=$ collaterals with slow but complete filling of the ischemic area by the late venous phase, $4=$ complete and rapid filling in the entire ischemic territory by retrograde perfusion). 
Table 1. Univariate analysis of data according to age

\begin{tabular}{|c|c|c|c|}
\hline Variable/group & $\begin{array}{l}\text { Younger than } 80 \\
(n=55)\end{array}$ & $\begin{array}{l}\text { Older than } 80 \\
(n=16)\end{array}$ & $\mathrm{p}$ \\
\hline Age, years & $63.1 \pm 12.5$ & $84.3 \pm 4.1$ & $<0.0001$ \\
\hline Gender, male & 27 (49) & $7(44)$ & 0.707 \\
\hline Occlusion site & & & 0.655 \\
\hline Proximal ICA & $4(7)$ & $1(6)$ & \\
\hline Proximal M1 MCA & $40(81)$ & $13(73)$ & \\
\hline Distal M1 MCA & $6(11)$ & $2(12)$ & \\
\hline Tandem ICA + MCA & $5(9)$ & 0 & \\
\hline Involved hemisphere, left & $30(55)$ & $6(38)$ & 0.230 \\
\hline Hypertension & $38(69)$ & $14(87)$ & 0.143 \\
\hline Ischemic heart disease & $29(53)$ & $8(50)$ & 0.848 \\
\hline Atrial fibrillation & $28(56)$ & $9(57)$ & 0.707 \\
\hline Diabetes mellitus & $19(35)$ & $4(25)$ & 0.473 \\
\hline Hyperlipidemia & $27(49)$ & $7(44)$ & 0.707 \\
\hline Smoking & $14(26)$ & $3(19)$ & 0.580 \\
\hline Previous stroke & $11(20)$ & $5(31)$ & 0.343 \\
\hline Bridging tPA given & $21(38)$ & $7(44)$ & 0.688 \\
\hline TOAST classification & & & 0.836 \\
\hline Cardioembolic & $38(69)$ & $12(75)$ & \\
\hline Large vessel & $9(16)$ & 3 (19) & \\
\hline Other & $1(2)$ & 0 & \\
\hline Unknown & 7 (13) & $1(6)$ & \\
\hline Admission NIHSS & $18.2 \pm 5.5$ & $18.4 \pm 7.3$ & 0.927 \\
\hline Discharge NIHSS & $7.9 \pm 8.1$ & $12.0 \pm 11.2$ & 0.138 \\
\hline Delta NIHSS & $10.5 \pm 6.0$ & $7.1 \pm 7.9$ & 0.084 \\
\hline 90-day mRS 0-2 & $27(57)^{\mathrm{a}}$ & $3(21)^{\mathrm{b}}$ & \\
\hline Mortality & $4(7)$ & $6(40)$ & 0.001 \\
\hline
\end{tabular}

Figures are means \pm SD or $\mathrm{n}(\%)$. ICA = Internal carotid artery; MCA = middle cerebral artery.

${ }^{\mathrm{a}}$ Total number $=47 .{ }^{\mathrm{b}}$ Total number $=14$.

Our standard treatment protocol in patients with large vessel occlusions included in the study suggests going directly to SRT if the treatment is immediately available and to use bridging with tPA if the SRT is not immediately available. All patients underwent SRT with the solitaire device (Medtronic USA). Failure to achieve recanalization led to use of further devices such as the pREset ${ }^{\circledR}$ LITE Thrombectomy Device (Phenox $\mathrm{GmbH}$ ) or thrombus aspiration. Treatment complications including post-procedure hemorrhage and clinical deterioration without hemorrhage were also documented. Symptomatic hemorrhage was classified according to published criteria [12].

Statistical evaluations were performed using SPSS PASW 22 (IBM). For univariate analysis patients were compared using Student's t test for continuous variables or $\chi^{2}$ test for categorical variables. Bivariate logistic regressions models were then used to test the effects of age over 80 on favorable outcome and survival. The models incorporated NIHSS scores, collateral grading and reperfusion status.

\section{Results}

Seventy-one consecutive patients fulfilling entry criteria were recruited into this preliminary study. Of those, 16 were older than 80 and represented the study group (median age $82.5,28 \%$ men). They were compared to the reminder of the patients (55) that were younger than 80 at the time of presentation (median age 62.5, 59\% men). The baseline clinical and radiological characteristics are presented in table 1 . All patients were independent prior to 
Table 2. Comparison of procedure- and post-procedure-associated variables

\begin{tabular}{lccc}
\hline Variable/group & $\begin{array}{l}\text { Younger than } 80 \\
(\mathrm{n}=55)\end{array}$ & $\begin{array}{l}\text { Older than } 80 \\
(\mathrm{n}=16)\end{array}$ & $\mathrm{p}$ \\
\hline Onset to SRT, min & $232.0 \pm 110.9$ & $239.5 \pm 129.9$ & 0.828 \\
Onset to recanalization, min & $276.7 \pm 114.6$ & $279.5 \pm 135.0$ & 0.938 \\
Favorable collaterals (grade 3-4) & $16(31)$ & $2(13)$ & 0.137 \\
$\begin{array}{l}\text { Post-procedure TICI } \\
\quad \text { 0-2a }\end{array}$ & $7(13)$ & $2(12)$ & 0.836 \\
$\quad$ 2b-3 & $47(87)$ & $14(88)$ & \\
Intracerebral hemorrhage & $7(13)$ & $6(38)$ & 0.029 \\
$\quad$ All & $1(2)$ & $2(13)$ & 0.132 \\
\hline
\end{tabular}

Figures are means $\pm \mathrm{SD}$ or $\mathrm{n}(\%)$.

the procedure ( $\mathrm{mRS} \leq 2$ ). Octogenarians did not differ in demographics and baseline criteria form younger patients. Of note, procedure-related variables including type and site of vessel occlusion, onset-to-treatment time and time to vessel recanalization, number and types of procedural modalities used and lesion length did not differ between the groups (table 2). Adequate target vessel recanalization (TICI $2 b-3$ ) also did not differ between the groups (table 2)

Favorable outcome at 90 days ( $\mathrm{mRS} \leq 2$ ) was more common in younger patients (77 vs. $23 \% ; \mathrm{p}=0.031$ ). In contrast, mortality rates were higher in octogenarians (40 vs. $7 \% ; \mathrm{p}=$ $0.01)$. Fatalities were due to infections or neurological deteriorations in all cases and did not involve withdrawal of life support in any of our patients.

Thirteen of our patients (18\%) had hemorrhagic transformation of their infarcts, but only 3 of these (4\%) were classified as symptomatic since they had confluent parenchymal hematoma that resulted in neurological worsening. Of these, 2 were in the older than 80 group and 1 in the younger group.

Logistic regression analysis adjusting for neurological severity and collateral state identified age over 80 (odds ratio, OR 0.15, 95\% CI 0.03-0.75; $\mathrm{p}=0.02$ ) and reperfusion state (OR $7.4,95 \%$ CI 1.1-49.9; $p=0.04$ ) as significant modifiers of favorable outcome. Similarly, age over 80 was identified as a positive predictor of mortality (OR 8.1,95\% CI 1.8-36.7; p = $0.007)$.

\section{Discussion}

The current preliminary study further expands the existing knowledge regarding the efficacy of SRT in older patients with large and often deadly strokes. This is particularly important as the population in the world grows substantially older and many more octogenarians will likely present with large hemispheric strokes in the upcoming years, leading to the creation of a large burden on intensive care services. Recently, published studies provided further evidence supporting the use of SRT in patients with large proximal vessel occlusions but largely excluded older patients. Nevertheless, prior studies have shown that systemic thrombolysis is generally effective in patients older than 80 despite higher mortality rates [25], and the use of SRT that allows for rapid and more complete recanalization raised hopes for better outcomes in older patients with large strokes as well. However, favorable outcomes 
were observed less often and mortality rates were significantly increased in our octogenarian patients despite similar rates of excellent recanalization. Our results are in agreement with those of previous studies [17-19, 26, 27], including some that used stentrievers [28], but do show that it is still possible to achieve favorable outcomes even in the very old. Similar results were also seen in a recently published meta-analysis of individual patient data from five recent trials that showed that the odds ratio of favorable outcome were higher in patients older than 80 treated with thrombectomy compared with those treated with tPA [29]. The reason for the discrepancy between our results and this analysis remain unclear but may suggest a more rigorous patient selection process in the trials included in the meta-analysis. Furthermore, only 198 of 1,278 patients in this analysis were older than 80, and whether stroke severity was lower in these patients compared to younger patients is not known. Interestingly, a recent study found that in order for older patients to have favorable outcome, the initial core needs to be much smaller [30]. Furthermore, age was found to be an important modulator of futile recanalization and poor outcome after adjusting for recanalization state in another study [31], suggesting that the impact of age on outcome may be not solely depend on vessel recanalization.

Importantly, in the current study, octogenarians presented with similar stroke severity, etiology, and similar onset-to-treatment and onset-to-recanalization time frames compared to younger patients. Admission to intensive care was a prerequisite of this study and therefore, admission settings are also not responsible for the discrepant results between younger patients and octogenarians. The low symptomatic intracerebral hemorrhage rates obtained in our group of patients is also reassuring that such patients may still be good candidates for therapy and that the rate of symptomatic intracerebral hemorrhage is not responsible for the increased frequency of poor outcome observed in elderly patients. Older patients may have poor outcome more frequently due to higher frequencies of concomitant disease and poor recuperation and rehabilitation capabilities compared to younger patients.

Importantly, several of our elderly patients did reach mRS 2 and several others reached mRS 3, which may still be looked upon as a reasonable outcome in patients with very large stroke since these patients are still able to ambulate. These results do show an improvement over those obtained with prior-generation endovascular techniques attesting to the superiority of SRT. Furthermore, chronological age does not always equal biological age and therefore, some octogenarians will still likely do well with treatment. Hence, we certainly cannot recommend withholding therapy in octogenarians despite the high costs and the low chances for good functional outcome. However, our results and those of others [17-19, 26, 27] suggest that prognosis should be more guarded in older patients.

Our study is limited by a relatively small number of included patients and therefore, we cannot exclude the possibility of missing statistical significance due to low power. Nevertheless, our results can be viewed as hypothesis generating, and larger randomized studies exploring outcome after SRT in younger versus older patients and the cost-effectiveness of this strategy should be carried out in the future. In light of our findings as well as those of others, it will be interesting to explore in the future whether direct SRT may be superior to bridging with tPA in patients with large artery occlusions.

In conclusion, SRT may be beneficial for most patients with large hemispheric strokes and may also improve outcome in older patients. Variables associated with increased chances of survival and good outcome including successful recanalization can only be determined during angiography. Therefore, our results suggest that efforts to recanalize the occluded artery may be considered in all patients with distal internal carotid or proximal middle artery occlusions but that prognostication should be guarded in the very old patients. 
Cohen et al.: Stent Retriever-Based Thrombectomy in Octogenarians

\section{Acknowledgements}

This work was supported by the Peritz and Chantal Scheinberg Cerebrovascular Research Fund and by the Sol Irwin Juni Trust Fund.

\section{Disclosure Statement}

All authors hereby declare they had no conflicts of interest.

\section{References}

1 Berrouschot J, Sterker M, Bettin S, Koster J, Schneider D: Mortality of space-occupying ('malignant') middle cerebral artery infarction under conservative intensive care. Intensive Care Med 1998;24:620-623.

2 Hacke W, Schwab S, Horn M, Spranger M, De Georgia M, von Kummer R: 'Malignant' middle cerebral artery territory infarction: clinical course and prognostic signs. Arch Neurol 1996;53:309-315.

3 Christou I, Felberg RA, Demchuk AM, Burgin WS, Malkoff M, Grotta JC, Alexandrov AV: Intravenous tissue plasminogen activator and flow improvement in acute ischemic stroke patients with internal carotid artery occlusion. J Neuroimaging 2002;12:119-123.

4 Derex L, Hermier M, Adeleine P, Pialat JB, Wiart M, Berthezene Y, Froment JC, Trouillas P, Nighoghossian N: Influence of the site of arterial occlusion on multiple baseline hemodynamic MRI parameters and post-thrombolytic recanalization in acute stroke. Neuroradiology 2004;46:883-887.

5 Lee KY, Han SW, Kim SH, Nam HS, Ahn SW, Kim DJ, Seo SH, Kim DI, Heo JH: Early recanalization after intravenous administration of recombinant tissue plasminogen activator as assessed by pre- and post-thrombolytic angiography in acute ischemic stroke patients. Stroke 2007;38:192-193.

6 Linfante I, Llinas RH, Selim M, Chaves C, Kumar S, Parker RA, Caplan LR, Schlaug G: Clinical and vascular outcome in internal carotid artery versus middle cerebral artery occlusions after intravenous tissue plasminogen activator. Stroke 2002;33:2066-2071.

7 Berkhemer OA, Fransen PS, Beumer D, van den Berg LA, Lingsma HF, Yoo AJ, Schonewille WJ, Vos JA Nederkoorn PJ, Wermer MJ, et al: A randomized trial of intraarterial treatment for acute ischemic stroke. N Engl J Med 2015;372:11-20.

8 Campbell BC, Donnan GA, Lees KR, Hacke W, Khatri P, Hill MD, Goyal M, Mitchell PJ, Saver JL, Diener HC, et al: Endovascular stent thrombectomy: the new standard of care for large vessel ischaemic stroke. Lancet Neurol 2015;14:846-854.

9 Campbell BC, Mitchell PJ, Kleinig TJ, Dewey HM, Churilov L, Yassi N, Yan B, Dowling RJ, Parsons MW, Oxley TJ, et al: Endovascular therapy for ischemic stroke with perfusion-imaging selection. N Engl J Med 2015;372: 1009-1018.

10 Goyal M, Demchuk AM, Menon BK, Eesa M, Rempel JL, Thornton J, Roy D, Jovin TG, Willinsky RA, Sapkota BL, et al: Randomized assessment of rapid endovascular treatment of ischemic stroke. N Engl J Med 2015;372: 1019-1030.

11 Jovin TG, Chamorro A, Cobo E, de Miquel MA, Molina CA, Rovira A, San Roman L, Serena J, Abilleira S, Ribo M, et al: Thrombectomy within $8 \mathrm{~h}$ after symptom onset in ischemic stroke. N Engl J Med 2015;372:2296-2306.

12 Saver JL, Goyal M, Bonafe A, Diener HC, Levy EI, Pereira VM, Albers GW, Cognard C, Cohen DJ, Hacke W, et al: Stent-retriever thrombectomy after intravenous t-PA vs. t-PA alone in stroke. N Engl J Med 2015;372:22852295.

13 Combined intravenous and intra-arterial recanalization for acute ischemic stroke: the Interventional Management of Stroke Study. Stroke 2004;35:904-911.

14 Alexandrov AV, Molina CA, Grotta JC, Garami Z, Ford SR, Alvarez-Sabin J, Montaner J, Saqqur M, Demchuk AM, Moye LA, et al: Ultrasound-enhanced systemic thrombolysis for acute ischemic stroke. N Engl J Med 2004;351: 2170-2178.

15 Smith WS, Sung G, Saver J, Budzik R, Duckwiler G, Liebeskind DS, Lutsep HL, Rymer MM, Higashida RT, Starkman S, et al: Mechanical thrombectomy for acute ischemic stroke: final results of the Multi MERCI trial. Stroke 2008;39:1205-1212.

16 Khatri P, Hill MD, Palesch YY, Spilker J, Jauch EC, Carrozzella JA, Demchuk AM, Martin R, Mauldin P, Dillon C, et al: Methodology of the Interventional Management of Stroke III Trial. Int J Stroke 2008;3:130-137.

17 Arkadir D, Eichel R, Gomori JM, Ben Hur T, Cohen JE, Leker RR: Multimodal reperfusion therapy for large hemispheric infarcts in octogenarians: is good outcome a realistic goal? AJNR Am J Neuroradiol 2012;33:11671169.

18 Prabhakaran S, Jovin TG, Tayal AH, Hussain MS, Nguyen TN, Sheth KN, Terry JB, Nogueira RG, Horev A, Gandhi D, et al: Posttreatment variables improve outcome prediction after intra-arterial therapy for acute ischemic stroke. Cerebrovasc Dis 2014;37:356-363. 
19 Singer OC, Haring HP, Trenkler J, Nolte CH, Bohner G, Reich A, Wiesmann M, Bussmeyer M, Mpotsaris A, Neumann-Haefelin T, et al: Age dependency of successful recanalization in anterior circulation stroke: the ENDOSTROKE study. Cerebrovasc Dis 2013;36:437-445.

20 Cohen JE, Leker RR: Revascularization-outcome paradox: not only time and collaterals status, but also complete recanalization contribute to good neurological outcome. Int J Stroke 2013;8:542-544.

21 Adams HP Jr, Bendixen BH, Kappelle LJ, Biller J, Love BB, Gordon DL, Marsh EE 3rd: Classification of subtype of acute ischemic stroke. Definitions for use in a multicenter clinical trial. TOAST. Trial of Org 10172 in Acute Stroke Treatment. Stroke 1993;24:35-41.

22 Brott T, Adams HP Jr, Olinger CP, Marler JR, Barsan WG, Biller J, Spilker J, Holleran R, Eberle R, Hertzberg V, et al: Measurements of acute cerebral infarction: a clinical examination scale. Stroke 1989;20:864-870.

23 Rankin J: Cerebral vascular accidents in patients over the age of 60. II. Prognosis. Scott Med J 1957;2:200-215.

24 Higashida RT, Furlan AJ, Roberts H, Tomsick T, Connors B, Barr J, Dillon W, Warach S, Broderick J, Tilley B, et al: Trial design and reporting standards for intra-arterial cerebral thrombolysis for acute ischemic stroke. Stroke 2003;34:e109-e137.

25 Ford GA, Ahmed N, Azevedo E, Grond M, Larrue V, Lindsberg PJ, Toni D, Wahlgren N: Intravenous alteplase for stroke in those older than 80 years old. Stroke 2010;41:2568-2574.

26 Kim D, Ford GA, Kidwell CS, Starkman S, Vinuela F, Duckwiler GR, Jahan R, Saver JL, Investigators UI-AT: Intraarterial thrombolysis for acute stroke in patients 80 and older: a comparison of results in patients younger than 80 years. AJNR Am J Neuroradiol 2007;28:159-163.

27 Qureshi AI, Suri MF, Georgiadis AL, Vazquez G, Janjua NA: Intra-arterial recanalization techniques for patients 80 years or older with acute ischemic stroke: pooled analysis from 4 prospective studies. AJNR Am J Neuroradiol 2009;30:1184-1189.

28 Parrilla G, Carreon E, Zamarro J, Espinosa de Rueda M, Garcia-Villalba B, Marin F, Hernandez-Fernandez F, Morales A, Fernandez-Vivas M, Nunez R, et al: Recanalization and mortality rates of thrombectomy with stentretrievers in octogenarian patients with acute ischemic stroke. Cardiovasc Intervent Radiol 2015;38:288294.

29 Goyal M, Menon BK, van Zwam WH, Dippel DW, Mitchell PJ, Demchuk AM, Davalos A, Majoie CB, van der Lugt A, de Miquel MA, et al: Endovascular thrombectomy after large-vessel ischaemic stroke: a meta-analysis of individual patient data from five randomised trials. Lancet 2016;387:1723-1731.

30 Ribo M, Tomasello A, Lemus M, Rubiera M, Vert C, Flores A, Coscojuela P, Pagola J, Rodriguez-Luna D, Bonet S, et al: maximal admission core lesion compatible with favorable outcome in acute stroke patients undergoing endovascular procedures. Stroke 2015;46:2849-2852.

31 Hussein HM, Georgiadis AL, Vazquez G, Miley JT, Memon MZ, Mohammad YM, Christoforidis GA, Tariq N, Qureshi AI: Occurrence and predictors of futile recanalization following endovascular treatment among patients with acute ischemic stroke: a multicenter study. AJNR Am J Neuroradiol 2010;31:454-458. 